\title{
Phonetic factors in letter detection: A reevaluation
}

\author{
ADAM DREWNOWSKI \\ Rockefeller University, New York, New York 10021 \\ and \\ ALICE F. HEALY \\ University of Colorado, Boulder, Colorado 80309
}

\begin{abstract}
Three experiments in which subjects searched for the letter $e$ in printed text were conducted to examine the effects of phonetic factors in silent reading. In Experiment 1, subjects made more errors on silent es than on pronounced es, but silent es always occurred at the ends of words, whereas pronounced es occurred in the middle of words. In Experiment 2, all instances of the letter e occurred in the penultimate location in the words, and no effects of letter voicing were obtained. In Experiment 3, subjects made more errors on es in unstressed syllables than on es in stressed syllables in three-syllable words. However, this effect occurred only for es in the second and third syllables and only for the more common words. All three experiments yielded large effects of word frequency, which were reduced in passages printed in alternating typecase. It was concluded that letter detection is affected by syllable stress but not by letter voicing and that the stress effect depends on whether the subject is able to form reading units at the syllable level.
\end{abstract}

There is much evidence that phonetic recoding of text occurs in the course of silent reading. One of the most influential studies (Corcoran, 1966) demonstrated that subjects searching for instances of the letter e in printed text made more errors on words in which e was silent (as in the word time) than on words in which it was pronounced (as in the word well). The common interpretation of this result, also observed by other investigators (e.g., Chen, 1976; Coltheart, Hull, \& Slater, 1975; Locke, 1978; Mohan, 1978), is that subjects silently reading paragraphs of text scan the acoustic image of a word along with the visual stimulus. However, in normal English prose of the type used by Corcoran,

This research was supported in part by a grant from the Spencer Foundation to Yale University, National Science Foundation Grants BNS80-00263 to Yale University and BNS80-25020 to the University of Colorado, and National Institute of Child Health and Human Development Grant HD01994 to Haskins Laboratories. Adam Drewnowski was a Postdoctoral Fellow at the University of Toronto under Grant APA 146 from the National Research Council of Canada during the conduct of these experiments. Alice F. Healy was supported by a Senior Faculty Fellowship from Yale University during the initial preparation of this manuscript. We are indebted to Doris Glavanov, Mary LaRue, Michele Noe, and Cheryl Wright for help with the conduct and analysis of the three experiments and to W. K. Estes, B. B. Murdock, and G. Wolford for helpful discussions about this research. Parts of this paper were presented at the Sixth Annual Interdisciplinary Conference, Park City, Utah, January 19-23, 1981. Requests for reprints should be sent either to A. Drewnowski, Rockefeller University, New York, New York 10021, or to A. F. Healy, Department of Psychology, University of Colorado, Boulder, Colorado 80309. the voicing of the letter e is typically confounded with a number of other factors. For example, silent es are often found in terminal or penultimate locations within words (e.g., some, states), and many occur in frequent function words (e.g., have) or in morpheme suffixes (e.g., asked). Each of these variables has been shown to influence the number of errors in letter-detection tasks: More errors have been found when the target letter occurred at the end of words (Corcoran, 1966; Smith \& Groat, 1979), in frequent words (Healy, 1976, 1980), in function words (Drewnowski \& Healy, 1977; Schindler, 1978), and in some morpheme suffixes (Drewnowski \& Healy, 1980). In the present study, we used specially prepared texts that control for these variables in order to determine whether voicing of the target letter has a residual effect on the detection task. Our study was intended as a systematic reexamination of Corcoran's (1966) silente effect in an attempt to specify the nature and to determine the boundary conditions of the phenomenon.

Our previous research with the letter-detection task (Drewnowski \& Healy, 1977, 1980; Healy, 1976, 1980) has shown that subjects miss most letters in the most common words, suggesting that frequent words may often be perceived in terms of units that include more than one letter. According to our frequency-dependent unitization model, the constituent letters of the most frequent English words tend, in effect, to be concealed within the word, since they never reach the level of identification in the course of fluent reading.

In our view (Drewnowski \& Healy, 1977), reading 
involves processing in paraliel of units at various levels of the linguistic hierarchy: letters, letter groups, words, or phrases. The ease of unit formation depends on the frequency and spatial predictability of letter sequences (Drewnowski \& Healy, 1980), whole-word frequency (Healy, 1976, 1980), and the syntactic constraints of text (Drewnowski \& Healy, 1977). We have assumed that once processing at some higher level is complete, subjects move to the next location in the text without necessarily completing the processing at the letter level, at least not to the point of letter identification. Such incomplete processing at the letter level does not interfere with the comprehension of text, but it may account for the missing-letter effect, which we have observed for the most common suffix morphemes (Drewnowski \& Healy, 1980) and for the most frequent words (Drewnowski \& Healy, 1977; Healy, 1976, 1980).

This model leads us to predict that the type of phonetic effects observed will depend on whole-word frequency. If the more frequent words are indeed processed in terms of syllable or word units, rather than letter units, then phonetic effects at the letter level should be relatively unimportant. For common words, phonetic effects at the letter level, as exemplified by the difference in error rates between silent and pronounced es, may be less important than phonetic effects at some higher linguistic level, such as the level of the syllable. Thus, the phonetic effects examined here may be more closely aligned to the postlexical phonological codes investigated by Foss and Blank (1980) than to their prelexical phonetic codes. However, we envision phonetic units at the syllable level, as well as at the word level. This notion of a hierarchy of phonetic units, analogous to the hierarchy of visual units, is similar to that proposed earlier by LaBerge and Samuels (1974).

In the present study, we examined phonetic effects at the syllable level as well as at the letter level as a function of whole-word frequency. Specifically, we used both common and rare words to investigate the subjects' ability to detect the letter e in syllables that did or did not carry the primary word stress. In addition, we manipulated visual and linguistic features of text to determine the extent of their interactions with word frequency and phonetic factors in the course of silent reading. Understanding these multiple interactions should help us extend our theoretical conception of the reading process.

\section{EXPERIMENT 1}

The first experiment was designed to explore the acoustic scanning hypothesis (Corcoran, 1966) and the unitization model. The voicing of the target letter e (silent vs. pronounced) and the linguistic class of the target word (function vs. content) were independently varied. The voicing of the letter e deliberately covaried with its location within the word: Silent es were always terminal, whereas pronounced es always occurred in the interior of test words, as is typically the case in English. Also, because English function words are normally more frequent than content words, the function words that were selected as test words were, on the average, more frequent than the test content words. ${ }^{1}$

To determine the contribution of perceptual features and of the syntactic/semantic context to performance on the letter-detection task, the subjects were tested on four different passages. In addition to a standard prose passage, the subjects were presented a nonsense passage of scrambled words and a mixed-case prose passage in which alternating letters were typed in uppercase. Although such manipulations should not affect the acoustic scanning of the search text, they are expected to impede the formation of reading units larger than the letter (mixed-case passage) or reading units larger than the word (scrambled-word passage) and consequently should influence the incidence of letter-detection errors. A fourth passage of meaningless and unpronounceable letter strings containing instances of the letter $e$ in the same locations as the corresponding words in the prose passage was included to determine the effects of target location on task performance. (See Drewnowski \& Healy, 1977, and Healy, 1976, 1980, for similar passage manipulations.)

\section{Method}

Subjects. Eighty-two male and female students at the University of Toronto served as volunteer subjects in a group experiment, which was conducted in the classroom.

Design and Materials. Four 100-word passages, typed on separate sheets of paper, were constructed for the present experiment. The first passage, hereafter referred to as the "prose standard-case" passage, contained 16 test function words (see Schindler, 1978, for definition) and 16 test content words, all of which contained exactly one instance of the letter $e$, along with 68 filler words, none of which contained the letter e. All test words were either one or two syllables long and varied from three to seven letters in length. Eight of the function words were judged to possess a pronounced $\mathrm{e}$, which occurred in the middle of the word: they, their, them, her, after, under, over, himself. The mean frequency of usage of these words (from Kucera \& Francis, 1967) was 1,841 per million words of text. The other eight function words were judged to possess a silent $e$, which always occurred at the end of the word: are, have, those, one, above, like, since, whose. The mean frequency of these words was 1,868 . The 16 content words were similarly divided into 8 with pronounced es (well, men, years, get, very, later, given, power), with a mean frequency of 659 , and 8 with silent es (time, use, make, home, office, little, middle, course), with a mean frequency of 650 . Mean word frequency across the voicing conditions was approximately equal (pronounced: 1,250; silent: 1,259).

The second passage, hereafter referred to as the "prose mixed-case" passage, was identical to the prose standard-case passage, except that alternating letters were typed in upper-and lowercase. There were two versions of this passage. In one version ("even"), even letters were capitalized, whereas in the other version ("odd"), odd letters were capitalized. Half the subjects were shown the even version of the prose mixed-case passage and half were shown the odd version, so that the incidence of lowercase and uppercase es would be equated across test words and across subjects.

The third passage, hereafter referred to as the "scrambledword" passage, was derived from the prose passage. The order of 
Table 1

First Lines of the Four Search Passages Used in Experiment 1

Prose Standard Case

Prose Mixed Case (Even)

Scrambled Word

Scrambled Letter
Men who work very long hours pass too little time at home.

mEn WhO wOrK vErY IOnG hOu Rs PaSs ToO lItTIE tImE aT hOmE.

Men his with very only cloud pass little who time an home.

Mer wlo vrny weok hnog loirs posi tao hutlte tsme ah twse. the 32 test words embedded within the paragraph of text was the same as in the prose passage, but the order of the remaining 68 filler words (none of which contained the letter e) was now randomized so that the passage no longer made sense. Whenever two test words occurred together in the prose passage (e.g., little time), they were separated in the scrambled-word passage by a filler word (e.g., little who time), but otherwise, the test words retained their original positions. Such manipulations were intended to minimize the presence of syntactically correct units in an otherwise meaningless passage.

The fourth passage, hereafter referred to as the "scrambledletter" passage, was also derived from the prose standard-case passage. The letters in each of the 20 consecutive five-word strings in the prose standard-case passage were now randomized to produce meaningless letter strings that corresponded both in length and in the location of the letter e within the string to the words of the prose standard-case passage. The location of the "words" on the page, the paragraph format, and the punctuation marks were the same as in the prose standardcase passage. The first lines of the four passages are shown in Table 1.

Each passage was typed on a separate sheet of paper. The four passages, arranged in all 24 possible sequences and preceded by a page of instructions to subjects, were stapled together into a booklet. The booklets were distributed according to a fixed rotation so that passage order was approximately counterbalanced across subjects.

Procedure. The subjects were instructed to read each passage silently at their normal reading speed and to circle each instance of the target $e$. The subjects were told that if they ever realized that they had missed a target, they should not retrace their steps to encircle it. They were also told that they were not expected to detect all the es, so they should not slow down their reading speed in order to be overcautious about encircling the es. The subjects were told to read the passages in the order in which they were stapled together and to go on to the next passage as soon as they had finished the preceding one.

\section{Results}

The results are summarized in Table 2, which includes for the four passages means and standard errors of the means for percentage error scores as a function of the voicing of the target letter and the class of the test word. More errors occurred on silent than on pronounced es $[F(1,81)=92.0, p<.01]$, and more errors were made on function words than on content words $[F(1,81)=74.4, p<.01]$. In addition, the difference in error rates between the pronounced and the silent es was greater for function words than for content words; there was a significant interaction between word class and voicing $[F(1,81)=29.4, p<.01]$.

The subjects performed similarly on both the prose standard-case and scrambled-word passages (mean overall error percentages: 17.7 for prose standard case; 16.3 for scrambled word) and were relatively more accurate on the prose mixed-case (15.4) and on the scrambledletter (9.5) passages $[F(3,243)=9.3, p<.01]$. The difference in error percentages between function words and content words was greater for the prose standard. case and the scrambled-word passages than for the prose mixed-case and the scrambled-letter passages. The interaction between word class and passage type $[F(3,243)=3.1, p<.05]$ supports our view that intact word units are necessary for the missing-letter effect. The difference in error percentages between silent es and pronounced es also depended on passage type; the interaction between voicing and passage type was significant $[F(3,243)=2.8, \quad p<.05]$. Nevertheless, even in the nonsense scrambled-letter passage, the difference between "pronounced" and "silent" es was significant, at the equivalents of both function word $[\mathrm{t}(81)=3.7, \mathrm{p}<.01]$ and conternt word $[\mathrm{t}(81)=2.3$, $p<.01]$ locations. Since "pronounced" es always occurred in the middle and "silent" es always at the end of the nonword letter strings, these findings suggest that error rates in the letter-detection task may be strongly influenced by target location.

\section{Discussion}

The present results are consistent with Corcoran's (1966) finding that subjects searching for instances of the target letter e made more detection errors on silent than on pronounced es. However, the results are equally

Table 2

Means and Standard Errors for Error Percentages as a Function of Passage Type, Voicing of the Target Letter, and Word Class in Experiment 1

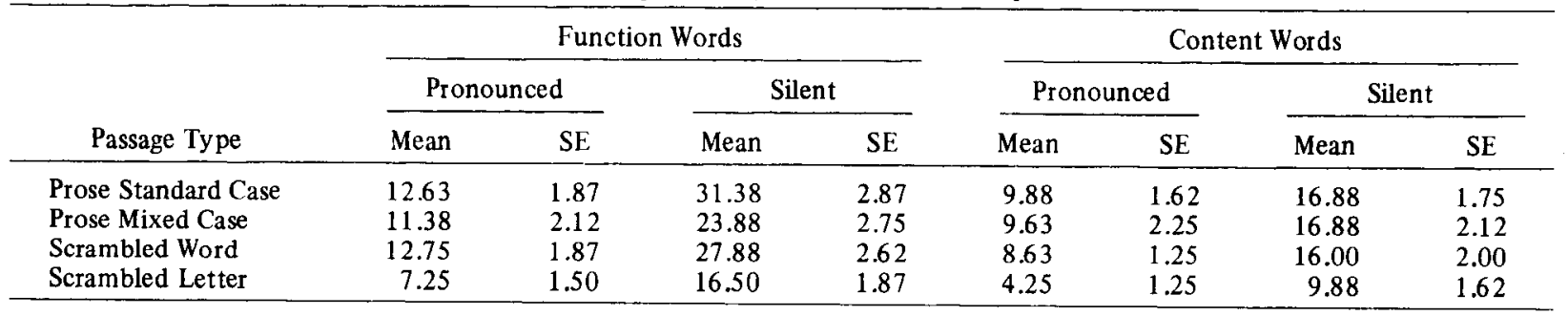


consistent with our previous reports (Drewnowski \& Healy, 1977, 1980; Healy, 1976, 1980) that subjects searching for a given target letter make most letterdetection errors on the most frequent function words. Subjects in this experiment made more errors on the more frequent function words than on the less frequent content words.

Thus, the complete pattern of results cannot be explained solely in terms of Corcoran's (1966) hypothesis that subjects tend to scan the acoustic image of the target word in the course of the letter-detection task. The simple notion of phonetic encoding during silent reading fails to account for the higher error percentages observed with function than with content words. Corcoran's (1966) explanation for the high error rates on the word the, which were more than double those on words containing silent es, was that the word the is a highly redundant word, which may be taken for granted and thus not scanned. The present results demonstrate, first, that the same missing-letter effect holds for other, less frequent, and presumably less redundant function words (mean frequency 1,854 as opposed to 69,971 for the), and second, that it holds even for the scrambled-word passage, in which the occurrence of any of the test words cannot be predicted on the basis of the preceding word context. Furthermore, the present results demonstrate that the difference in error percentages between pronounced and silent es is, if anything, much greater for the function words than for the content words, which is contrary to what one might expect if the function words were indeed redundant and therefore not scanned.

The pattern of results obtained in standard-case and mixed-case passages is also more consistent with our model than with Corcoran's (1966) phonetic recoding hypothesis. In our view, subjects make most letterdetection errors on the frequent function words in prose and scrambled-word passages because they tend to process highly frequent words in terms of units larger than the letter. The use of mixed-case passages impedes the formation of such reading units and might be expected, in effect, to unpack the processing of function words, making their constituent letters more visible. Consequently, error rates on function words and, to a lesser extent, on content words should be lower for the prose mixed-case passage relative to the prose standardcase passage, as was indeed observed. However, it could be argued that any text manipulation that slows down the reader would make the letters of function words easier to detect. Our earlier data (e.g., Drewnowski \& Healy, 1977; Healy, 1976) suggest, though, that only manipulations causing a spatial-configural disruption have this effect. The use of nonsense scrambled-word passages instead of prose slows down the reader but does not alter the relative proportion of errors on the word the (Healy, 1976). Another possible reason for fewer errors on the mixed-case passage is that capital letters may be easier to find than lowercase letters. Yet, even if such a result were obtained, it could not explain the selective drop in errors for frequent function words, which was not seen for content words.

Finally, the present data indicate that the observed silent-e effect may be due in large part to the differential location of the target letter $\mathrm{e}$ within the test word. Subjects searching the scrambled-letter passage for instances of the letter e made significantly more errors on the terminal "silent" locations than on the middle "pronounced" locations within the letter strings. This finding points to the presence of a strong target-location effect (which was in fact observed by Corcoran and suggests the need for another experiment in which the target-letter location within the word is rigidly controlled.

\section{EXPERIMENT 2}

In Experiment 2, we controlled for letter location by insuring that all target letters, both silent and pronounced; occurred in the penultimate position in the unstressed final syllable of a test word. Because of this constraint, the present comparison was between silent es and reduced or schwa-type es, rather than between silent es and nonreduced or full es. However, the schwatype $e$ is in fact a very frequent realization of the $e$ sound and, hence, presumably qualifies as a modal e (cf. Locke, 1978). Furthermore, the acoustic form of the e sound $(/ \mathrm{i} /, / \epsilon /$, or $/ \partial /)$ was found by Corcoran (1966) to have no influence on the frequency of letterdetection errors.

To control for the linguistic class of the test words, only content words were used. We also controlled two additional variables that were reported to affect the rate of letter-detection errors: (1) the length and frequency of the words containing the target letter (Drewnowski \& Healy, 1977; Healy, 1976, 1980), and (2) the linguistic environment of the target letter, which occurred either in a morpheme suffix or in the word stem (Drewnowski \& Healy, 1980). Finally, we employed a passage typed with standard typecase as well as one with mixed typecase, as we had in Experiment 1, to determine how voicing and the other variables tested in teract with visual factors.

\section{Method}

Subjects. Ninety-six male and female Yale undergraduates participated as subjects. The first 28 of them received course credit for their participation; the remaining 68 were paid $\$ 1$ each.

Design and Materials. Two 240-word nonsense passages were constructed. The passages included 48 test words, each of which included a single instance of the letter $e$ in the penultimate position. The test words were classified into eight groups of six words, on the basis of three orthogonal divisions: (1) words with e as part of a terminal morpheme suffix (e.g., higher) vs. words with e as part of the stem (order), (2) words in which the $\mathrm{e}$ is pronounced (higher) vs. words in which the $\mathrm{e}$ is silent (worked) ${ }^{2}$ (3) short words (one to two syllables) of high frequency $($ mean $=220$, range $=101-605 ;$ Ku'era \& Francis, 1967) (higher) vs. long words (three syllables) of low frequency (mean $=6$, range $1-12$ ) (container). Word length and frequency 
were treated here as a single variable, since longer English words are typically less frequent than shorter ones.

The specific test words employed are listed in Table 3. Note that three of the six words with a pronounced $e$ in the suffix end in er and three end in -ed for both the long infrequent and the short frequent words. This division allowed us to make two more controlled comparisons: The first was an assessment of test word ending (suffix vs. stem), including only words ending in -er. The second was an assessment of the effects of voicing, including only words ending in the ed suffix. For these comparisons, the terminal letters in the word ( $r$ or $d$ ) were not confounded with any of the critical variables.

The passages also included $\mathbf{4 8}$ foil words matched as closely as possible in syllabic length and frequency to the 48 test words (so that a subject could not determine whether a word contained a target on the basis of length or frequency alone), 48 filler words in the frequency range of 11-12, 48 filler words in the frequency range of 114-148, and 48 function filler words with frequency greater than or equal to 461 . None of the foil or filler words included the letter e, except for one filler word (stopped), which was included erroneously and was therefore not included in the error analyses reported below.

The test, foil, and filler words were arranged in the passage at random, with the constraint that every block of five successive words include one test, one foil, and three filler words, one of which was a function word. No punctuation was included in the passage except for a final period.

The two passages differed only in terms of letter capitalization. The standard-case passage was typed with only the initial letter of the initial word capitalized. The mixed-case passage was prepared in two versions: Even letters were capitalized in the even version and odd letters in the odd version.

Each subject was shown the standard-case passage along with either the even or odd version of the mixed-case passage. Half the subjects were shown the odd version and half were shown the even version. Each passage was typed on a separate sheet of paper and photocopied for distribution to the subjects. The order of presentation of standard-and mixed-case passages was perfectly counterbalanced across subjects. Copies of the two passages preceded by a consent form and a sheet of instructions were stapled together into a booklet for each subject.

Procedure. The procedure was essentially the same as that used in the previous experiment, except that subjects were run in groups of one to six.

\section{Results}

The results are summarized in Table 4, which includes for the two passage types (standard case and mixed case) the means and standard errors of the means for percentage error scores as a function of the voicing of the target letter (pronounced vs. silent), the frequency and the length of the test word (common vs. rare), and test word ending (suffix vs. stem).

The subjects made more errors on short common
Table 3

Test Words Used in Experiment 2

\begin{tabular}{|c|c|c|c|}
\hline \multicolumn{4}{|c|}{ Test Wọd Ending } \\
\hline \multicolumn{2}{|c|}{ Suffix } & \multicolumn{2}{|c|}{ Stem } \\
\hline Common & Rare & Common & Rare \\
\hline \multicolumn{4}{|c|}{ Pronounced } \\
\hline $\begin{array}{l}\text { higher } \\
\text { longer } \\
\text { lower } \\
\text { added } \\
\text { started } \\
\text { wanted }\end{array}$ & $\begin{array}{l}\text { container } \\
\text { blackmailer } \\
\text { narrower } \\
\text { contracted } \\
\text { disgusted } \\
\text { discarded }\end{array}$ & $\begin{array}{l}\text { order } \\
\text { summer } \\
\text { mother } \\
\text { system } \\
\text { market } \\
\text { women }\end{array}$ & $\begin{array}{l}\text { wallpaper } \\
\text { midsummer } \\
\text { hamburger } \\
\text { nitrogen } \\
\text { unravel } \\
\text { caramel }\end{array}$ \\
\hline \multicolumn{4}{|c|}{ Silent } \\
\hline $\begin{array}{l}\text { worked } \\
\text { walked } \\
\text { passed } \\
\text { turned } \\
\text { asked } \\
\text { showed }\end{array}$ & $\begin{array}{l}\text { diminished } \\
\text { commissioned } \\
\text { malnourished } \\
\text { impassioned } \\
\text { uniformed } \\
\text { abolished }\end{array}$ & $\begin{array}{l}\text { sides } \\
\text { times } \\
\text { values } \\
\text { rates } \\
\text { sales } \\
\text { states }\end{array}$ & $\begin{array}{l}\text { syllables } \\
\text { microphones } \\
\text { disclosures } \\
\text { limousines } \\
\text { contributes } \\
\text { signatures }\end{array}$ \\
\hline
\end{tabular}

words (19.2\%) than on long rare words (14.3\%) $[F(1,95)=27.8, p<.01]$ and on the standard-case version $(22.6 \%)$ than on the mixed-case version $(11.0 \%)$ of the passage $[\mathrm{F}(1,95)=123.5, \mathrm{p}<.01]$. The observed difference in error rates between common and rare words was greater for the standard-case passage $(26.7 \%$ vs. $18.5 \%)$ than for the mixed-case passage ( $11.7 \%$ vs. $10.2 \%)$. This significant interaction $[F(1,95)=20.3, p<.01]$ can be attributed to the fact that processing in the mixedcase passage largely occurs at the letter level.

Neither of the remaining variables yielded the expected effects. First, there was no difference in errors made on targets occurring in word stems (16.9\%) and those occurring in word suffixes (16.6\%). Second, slightly more errors were made on words in which the target e was pronounced $(17.4 \%)$ than on words in which the target e was silent $(16.1 \%)$. This difference was not statistically reliable $[F(1,95)=2.6, p>.10]$, but there was a significant interaction between voicing and passage type $[F(1,95)=27.9, p<.01]$. More errors were made on silent than on pronounced targets in the mixed-case passage (11.9\% vs. $10.0 \%$ ), but the opposite result was obtained in the standard-case passage $(20.4 \%$ vs. $24.8 \%$ ).

A further pair of comparisons was made to determine whether the failure to find the expected effects of voic-

Table 4

Means and Standard Errors for Error Percentages as a Function of Passage Type, Voicing of the Target Letter, Frequency of Test Word, and Test Word Ending for Experiment 2

\begin{tabular}{|c|c|c|c|c|c|c|c|c|c|}
\hline \multirow[b]{3}{*}{ Passage } & \multirow[b]{3}{*}{ Voicing } & \multicolumn{4}{|c|}{ Suffix } & \multicolumn{4}{|c|}{ Stem } \\
\hline & & \multicolumn{2}{|c|}{ Common } & \multicolumn{2}{|c|}{ Rare } & \multicolumn{2}{|c|}{ Common } & \multicolumn{2}{|c|}{ Rare } \\
\hline & & Mean & $\mathrm{SE}$ & Mean & $\mathrm{SE}$ & Mean & SE & Mean & SE \\
\hline Standard Case & $\begin{array}{l}\text { Pronounced } \\
\text { Silent }\end{array}$ & $\begin{array}{l}29.51 \\
25.52\end{array}$ & $\begin{array}{l}2.58 \\
2.49\end{array}$ & $\begin{array}{l}17.88 \\
18.40\end{array}$ & $\begin{array}{l}2.07 \\
2.45\end{array}$ & $\begin{array}{l}28.99 \\
22.92\end{array}$ & $\begin{array}{l}2.42 \\
2.52\end{array}$ & $\begin{array}{l}22.92 \\
14.58\end{array}$ & $\begin{array}{l}2.29 \\
1.96\end{array}$ \\
\hline Mixed Case & $\begin{array}{l}\text { Pronounced } \\
\text { Silent }\end{array}$ & $\begin{array}{l}10.42 \\
12.67\end{array}$ & $\begin{array}{l}1.44 \\
1.61\end{array}$ & $\begin{array}{r}7.99 \\
10.59\end{array}$ & $\begin{array}{l}1.35 \\
1.62\end{array}$ & $\begin{array}{r}9.55 \\
14.06\end{array}$ & $\begin{array}{l}1.37 \\
1.95\end{array}$ & $\begin{array}{l}12.15 \\
10.24\end{array}$ & $\begin{array}{l}1.65 \\
1.57\end{array}$ \\
\hline
\end{tabular}


ing and wordending type (suffix vs. stem) was due to a partial confounding of these factors with the specific terminal letter of the word. In the first analysis, which involved only words in which the target was pronounced and only words ending in -er, words in which the target occurred in the stem were compared with words in which the target occurred in the suffix. Even for these words, more errors were made when the target occurred in the stem $(24.7 \%)$ than when it occurred in the suffix $(16.8 \%)$, rather than the opposite $[F(1,95)=24.6$, $\mathrm{p}<.01]$. In the second analysis, which involved only words in which the target occurred in the suffix -ed (and hence none of those ending in nasal or liquid consonants), words in which the target was pronounced were compared with words, matched in terms of word frequency, in which the target was silent. There was no overall difference between errors on silent es $(16.8 \%)$ and on pronounced es $(16.1 \%)[F(1,95)<1]$, and for the standard-case passage alone, slightly more errors were made on pronounced es $(23.6 \%)$ than on silent es $(21.4 \%)$. It is therefore clear that the failure to find the expected effects of voicing and wordending type cannot be attributed to the specific terminal letter of the word.

\section{Discussion}

The primary purpose of this experiment was to determine whether the effects of letter voicing obtained in Experiment 1 could be attributed to the voicing of the target letter or to letter location. When letter location was strictly controlled, the typical effects of voicing-more errors on silent than on pronounced targets-were not obtained. Instead, no overall difference between silent and pronounced letters was found, and, in fact, a small difference in the direction opposite to that predicted was found for the standard version of the passage. Thus, the effects of letter voicing in Experiment 1 may be due to the confounding of voicing and letter location. Although Corcoran (1966) did control for letter location in one of his data analyses and still obtained significant effects of voicing, he did not control for word class or word frequency. It is possible that these factors may have influenced his results: For example, words with terminal or penultimate silent es may have included a disproportionate number of common words (e.g., are, have, or used). Furthermore, Corcoran's sample of pronounced es most likely included some that were stressed (e.g., he, be, or met), whereas our sample did not.

Not only does the present study fail to demonstrate the expected effects of voicing, but it also fails to demonstrate the expected effects of word ending: No more errors were made on letters occurring in word suffixes than on those occurring in word stems. This result is not in agreement with our earlier report (Drewnowski \& Healy, 1980). However, the earlier study dealt with the suffix -ing, whereas the present study deals with the suffixes -er and -ed. In fact, we previously noted that other suffixes, including -ment, -ion, and -en, did not yield as many detection errors as -ing and that -ing was special in a number of ways, including its high frequency and high spatial predictability. For that reason, it is not surprising that the morpheme suffixes we used in the present study did not yield a preponderance of detection errors.

In contrast, word frequency and length did yield large effects in the expected direction. In accord with the unitization model, many more errors were made on the short common words than on the longer rare words, and this effect was greatly diminished when every other letter was typed in capital letters.

\section{EXPERIMENT 3}

After controlling for target location and word frequency in Experiment 2, we failed to observe phonetic effects in the letter-detection task. However, all es were unstressed, and we were dealing exclusively with phonetic attributes at the letter level. Perhaps phonetic factors play a larger role at some higher level in the linguistic hierarchy. For example, subjects may make more errors on unstressed than on stressed syllables, since the stressed syllables would be expected to be more salient in a phonetically recoded version of the text. Therefore, in Experiment 3, we selected test words in which the target letter e either did or did not carry the primary word stress. In addition, we used both relatively frequent and relatively infrequent test words. We expected frequent words to be read at the syllable level or above and rare words to be read letter by letter. Consequently, the effects of syllable stress should be greater for the more frequent words.

As in previous experiments, we used standard-case and mixed-case passages. Since the formation of reading units larger than the letter should be impeded in the mixed-case passage, the effect of stress should be greatly reduced by means of this purely visual manipulation. In addition, because the results of Experiment 1 attest to the importance of target-letter location within the word, we now used three-syllable test words with the target letter occurring in the first, second, or third syllable of the word.

\section{Method}

Subjects. Ninety six male and female students at the University of Toronto served as volunteer subjects in this experiment, conducted in a classroom setting.

Design and Materials. Two 240-word scrambled-word passages were constructed for the present experiment. Each passage included the same 48 test words, with each word containing a single instance of the target letter $e$. The test words were classified into 12 groups of words on the basis of three orthogonal divisions: (1) the location of the target letter e, which was in the first, second, or third syllable of the word (e.g., certainly, attention, incorrect), (2) the presence or absence of primary word stress on the syllable containing the target letter (e.g., certainly vs. decision), and (3) the frequency in the language of the test word (e.g., certainly vs. decimal). The mean frequency of the more common words was 99.9 (Kučera \& Francis, 1967), and the mean frequency of the less 
Table 5

Test Words Used in Experiment 3

\begin{tabular}{|c|c|c|c|c|c|}
\hline \multicolumn{6}{|c|}{ Target Location } \\
\hline \multicolumn{2}{|c|}{ Syllable 1} & \multicolumn{2}{|c|}{ Syllable 2} & \multicolumn{2}{|c|}{ Syllable 3} \\
\hline Stressed & Unstressed & Stressed & Unstressed & Stressed & Unstressed \\
\hline \multicolumn{6}{|c|}{ High Frequency } \\
\hline $\begin{array}{l}\text { certainly } \\
\text { regular } \\
\text { technical } \\
\text { medical }\end{array}$ & $\begin{array}{l}\text { decision } \\
\text { religion } \\
\text { beginning } \\
\text { specific }\end{array}$ & $\begin{array}{l}\text { attention } \\
\text { directly } \\
\text { successful } \\
\text { professor }\end{array}$ & $\begin{array}{l}\text { suddenly } \\
\text { properly } \\
\text { governor } \\
\text { powerful }\end{array}$ & $\begin{array}{l}\text { incorrect } \\
\text { discontent } \\
\text { introspect } \\
\text { indirect }\end{array}$ & $\begin{array}{l}\text { consider } \\
\text { character } \\
\text { apartment } \\
\text { citizens }\end{array}$ \\
\hline \multicolumn{6}{|c|}{ Low Frequency } \\
\hline $\begin{array}{l}\text { decimal } \\
\text { terminal } \\
\text { democrats } \\
\text { sensory }\end{array}$ & $\begin{array}{l}\text { mechanic } \\
\text { revision } \\
\text { permitting } \\
\text { semantic }\end{array}$ & $\begin{array}{l}\text { collector } \\
\text { pathetic } \\
\text { compelling } \\
\text { appendix }\end{array}$ & $\begin{array}{l}\text { prophecy } \\
\text { prosperous } \\
\text { tolerant } \\
\text { numbering }\end{array}$ & $\begin{array}{l}\text { circumvent } \\
\text { dispossess } \\
\text { misdirect } \\
\text { unconcern }\end{array}$ & $\begin{array}{l}\text { immodest } \\
\text { disorders } \\
\text { concurrent } \\
\text { transparent }\end{array}$ \\
\hline
\end{tabular}

common words was 6.6. The high frequency test words stressed on the third syllable were necessarily less common than the remaining words in the high-frequency category. The specific test words employed are listed in Table 5. Note that the linguistic structure of the test words is not constant. For example, many test words with es in the first and second syllables end in morpheme suffixes (e.g., certainly), but those with es in the last syllable mostly do not. For that reason, we cannot be certain at this point that we have successfully controlled for the potential effects of other linguistic variables.

The two passages were composed of the 48 test words, 48 foil words selected to match the test words in number of syllables and approximate frequency, 96 filler words selected from an article in Psychology Today, and 48 of the most common function words selected from Kurera and Francis (1967). The foil words, filler words, and function words did not contain any instances of the letter e: All instances of $e$ in the passage thus occurred in the 48 test words.

The sequence of words in each passage was constructed with the same constraints used in Experiment 2. The two passages, standard case and mixed case (odd and even versions), were presented to the subjects in a counterbalanced order. Instructions to subjects and details of the testing procedure were the same as those described in the previous experiments.

\section{Results}

The results are summarized in Table 6, which includes for the two passages means and standard errors of the means for percentage error scores as a function of test word frequency and the presence or absence of stress on the letter $\mathrm{e}$.

The subjects made more errors on the high-frequency than on the low-frequency test words $[F(1,95)=39.6$, $\mathrm{p}<.01]$, in agreement with previous results. Overall, more errors were made on unstressed than on stressed es $[F(1,95)=8.6, p<.01]$, but the effect of stress was found only for the high-frequency words. The significant interaction between word frequency and stress $[F(1,95)=9.4, p<.01]$ is consistent with an earlier report (Smith \& Groat, 1979) and supports our hypothesis that common words are more likely to be read in syllable-size units and that, therefore, phonetic effects are more likely to occur at the syllable level. Further support for this hypothesis was provided by the finding that the effects of frequency and the effects of stress were larger in the standard-case passage, in which units larger than the letter could be formed, than in the mixed-case passage, in which the formation of such reading units was impeded. The interaction of frequency and passage type was significant $[F(1,95)=$ $5.4, \mathrm{p}<.05]$, and there was a weak interaction of stress and passage type $[F(1,95)=3.8, p=.05]$.

The effects of target location and syllable stress are shown in Figure 1 separately for standard-case and mixed-case passages. Target location (first, second, or third syllable of the test word) significantly affected error rates: More errors were made on es in the second and third syllables of test words than on es in the first syllable $[F(2,190)=8.6, p<.01]$. As in Experiment 1 , the target-location effect was higher for the standardcase passage than for the mixed-case passage: The interaction of passage type and target location was significant $[\mathrm{F}(2,190)=6.6, \mathrm{p}<.01]$.

These results suggest that subjects use reading units of different sizes at the different locations within the word. If subjects reading three-syllable words do make

Table 6

Means and Standard Errors for Error Percentages as a Function of Passage Type, Word Frequency, and Syllable Stress in Experiment 3

\begin{tabular}{|c|c|c|c|c|c|c|c|c|}
\hline \multirow[b]{3}{*}{ Frequency } & \multicolumn{4}{|c|}{ Standard-Case Passage } & \multicolumn{4}{|c|}{ Mixed-Case Passage } \\
\hline & \multicolumn{2}{|c|}{ Stressed } & \multicolumn{2}{|c|}{ Unstressed } & \multicolumn{2}{|c|}{ Stressed } & \multicolumn{2}{|c|}{ Unstressed } \\
\hline & Mean & $\mathrm{SE}$ & Mean & SE & Mean & SE & Mean & SE \\
\hline High & 12.7 & 1.6 & 18.3 & 1.8 & 12.6 & 1.5 & 14.2 & 1.6 \\
\hline Low & 9.7 & 1.5 & 9.7 & 1.3 & 10.6 & 1.7 & 10.5 & 1.5 \\
\hline
\end{tabular}




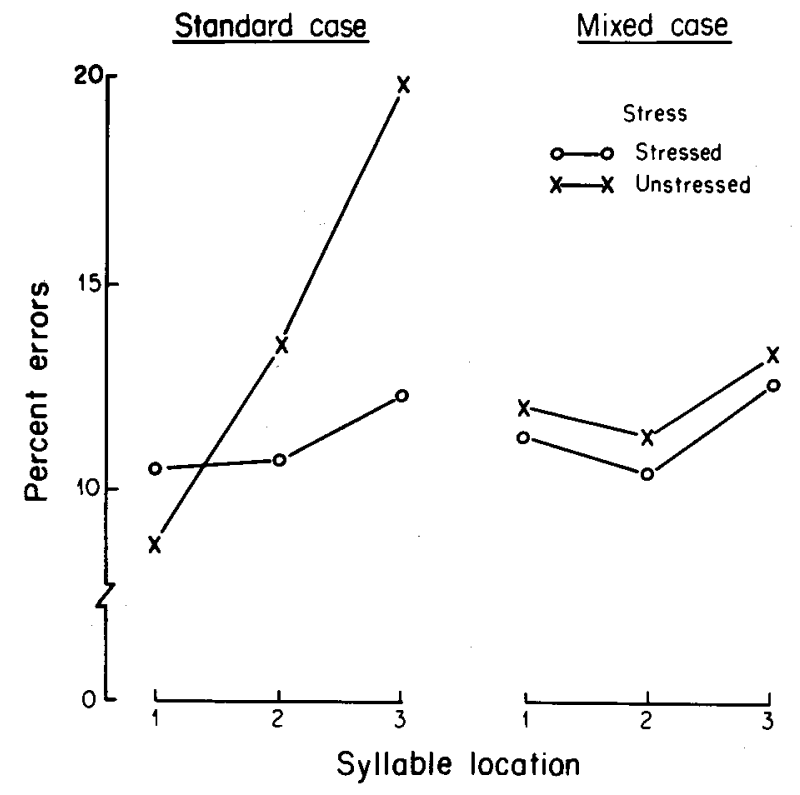

Figure 1. Error percentages as a function of passage type, syllable stress, and target location in Experiment 3.

use of reading units larger than the letter only in the second and third syllables of words, then we might expect the effect of syllable stress to interact with target location; the effect of stress should be greater in the later locations within the test word, especially in the standard-case passage. In accordance with these predictions, we found significant interactions between target location and syllable stress $[F(2,190)=5.0$, $\mathrm{p}<.01]$ and among passage type, target location, and syllable stress $[\mathrm{F}(2,190)=5.0, \mathrm{p}<.01]$.

We have proposed that infrequent words are less likely than frequent words to be read in syllable units. Hence, the effects of passage type, target location, and syllable stress should be more evident for the highfrequency test words. Figure 2 shows error percen tages as a function of word frequency, target location, and syllable stress. Only the data from the standard-case passage are included, since little difference between the various conditions was observed for the mixed-case passage. The highest error scores were obtained for unstressed es occurring in the second and third syllables of high-frequency test words. There was a significant interaction between word frequency and target location $[F(2,190)=6.3, p<.01]$ and a significant four-way interaction among word frequency, passage type, target location, and syllable stress $[\mathrm{F}(2,190)=3.5, \mathrm{p}<.01]$ (Note, however, that the observed drop in error rate for third-syllable stressed es in high-frequency words may be partly due to the fact that these words were relatively infrequent, as noted in the Method section.)

\section{Discussion}

In Experiment 3, we found significant effects of syllable stress, with more errors made on targets occurring in unstressed than in stressed syllables. However, these effects were by no means general but, rather, occurred only under narrowly defined circumstances. Effects of stress were not observed for the mixed-case passage, for infrequent test words, or for targets occurring in the first syllable of test words. We propose a common explanation for the lack of stress effects in each of these cases: Because we assume that the stress effect is a phonetic effect at the syllable level, no effects of stress should be observed when units larger than the letter are not used. Consequently, the effects of stress should be attenuated for mixed-case passages and for infrequent words. We also propose that subjects read longer content words in terms of different-size units at different locations of the word. Specifically, subjects may process the first syllable of three-syllable words to the point of identifying each letter but use reading units larger than the letter in later locations of the word. By this explanation, the effects of stress, which occur at the syllable level, are most likely to be found in the later locations of relatively common words, as was, indeed, observed. To summarize, it appears that stress effects occur only when the subject is able to form reading units at the syllable level.

It is possible that the observed difference between es in unstressed and stressed syllables is due to a difference between reduced (or schwa-type) and nonreduced

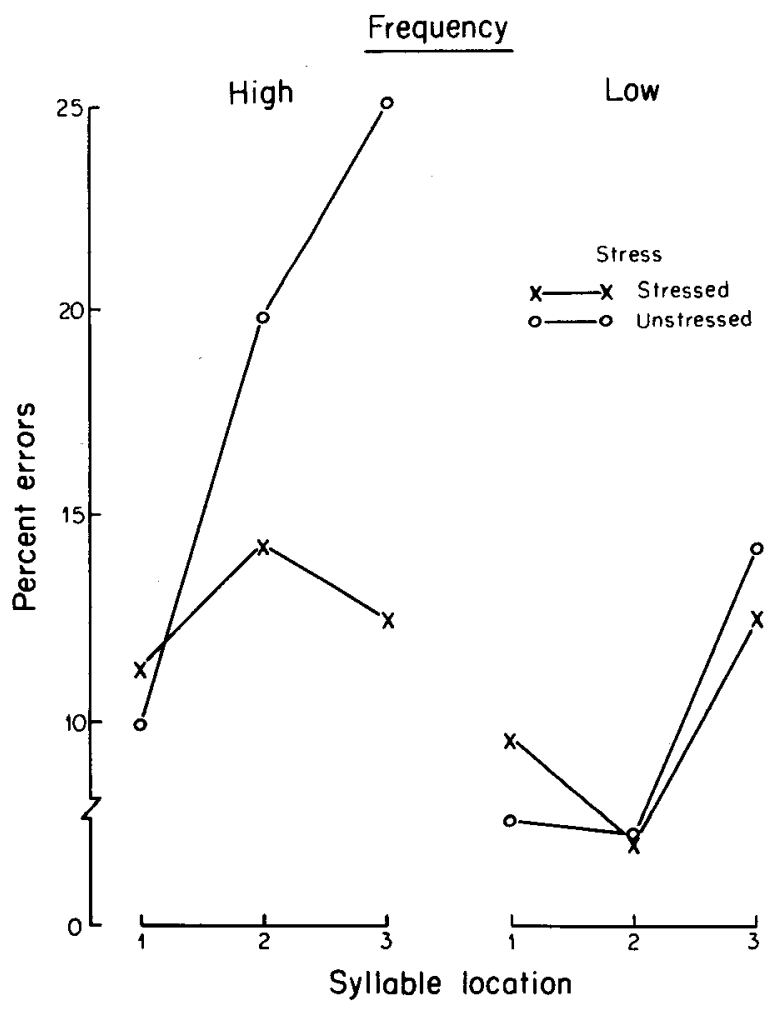

Figure 2. Error percentages as a function of word frequency, syllable stress, and target location for standard-case passage in Experiment 3. 
(or fuil) es. All stressed es in the present experiment were nonreduced, whereas all unstressed es in the second and third syllables (but not the first syllable) were reduced. This explanation is consistent with the observed interaction between target location and syllable stress, but it cannot account for the interactions between syllable stress and test word frequency or between syllable stress and passage typecase.

It can also be argued that the location effect found here (and the similar effect in Experiment 1) is caused by subjects' scanning only the initial syllable of the test word for target letters and failing to scan the remainder of the word. However, this account is not consistent with our finding a stress effect for the second and third syllables of test words. If subjects failed to scan the end of the word, then there should not be a difference between stressed and unstressed syllables at the end of the word.

It may seem puzzling that subjects make many errors on short frequent words (e.g., the) and few errors on the initial syllables of longer, less frequent words (e.g., certainly). However, the unitization model is compatible with these results because of the postulate that subjects move their attention to the next word in the text, without completing processing at the letter level, once they have identified a particular configuration as a word. For example, subjects will not complete processing of the letters in the word the once they have identified the familiar configuration as a word.

\section{GENERAL DISCUSSION}

One recurring issue in studies of reading is the extent to which phonetic factors are involved in the process of silent reading. Although many studies have addressed this issue (see McCusker, Hillinger, \& Bias, 1981, for a detailed review), most were limited to situations involv. ing the presentation of isolated words and pseudowords, as in the lexical decision task. Little is known about the extent of phonetic recoding in the course of normal comprehension of printed text.

Our technique of letter detection in prose contexts (Corcoran, 1966; Healy, 1976) provides a good index of performance during normal silent reading. Indeed, the pattern of errors on the letter-detection task can be used as a reading diagnostic, since we have demonstrated in developmental studies that error rates vary as a function both of the reading materials and of the subjects' reading skill (Drewnowski, 1978, 1981). In our previous studies, we have used the letter-detection technique to examine the size of the units employed in reading printed text. In contrast, most investigators using this technique have focused on the phonetic recoding hypothesis, by comparing error rates either on silent and pronounced letters (Chen, 1976; Coltheart et al., 1975; Corcoran, 1966; Mohan, 1978; Smith \& Groat, 1979) or on modal and nonmodal phonemes (Locke, 1978). However, the use of normal English in this task carries with it important confoundings. In the present study, we designed special passages to eliminate the confoundings of target-letter location, test word frequency, and linguistic context in order to determine whether the voicing of the target letter has a residual effect on error rates.

The study provided further support for the unitization model. All three experiments revealed clear effects of word frequency: More errors were made on frequent than on less frequent words. In Experiment 1, word frequency covaried with linguistic class (function vs. content words), whereas in Experiment 2, word frequency covaried with word length. Both factors were controlled in Experiment 3, which included only threesyllable content words and still revealed a significant effect of word frequency. This frequency effect is consistent with the previous observations by Healy $(1976,1980)$ and supports the hypothesis that subjects are more likely to read common than rare words in units larger than the letter, even in the case of long content words. The effect of frequency is considerably more dramatic for the most frequent function words the and and (see Drewnowski \& Healy, 1977).

In agreement with previous reports (e.g., Corcoran, 1966), we found in Experiment 1 that subjects made more errors on silent than on pronounced es. However, the voicing of the target letter covaried with letter location within the word. A similar difference between "silent" and "pronounced" locations was found in the scrambled-letter passage composed of unpronounceable letter strings, suggesting that letter location rather than letter voicing might be the more important factor. When the location of the target letter was strictly controlled, as it was in Experiment 2, no effects of voicing were obtained. The effects of voicing noted by previous investigators who did control for location may have been due to a confounding of letter voicing and word frequency. In Experiment 2, no effect of voicing was obtained either for high-frequency or low-frequency test words.

We did obtain phonetic effects in Experiment 3 in which we systematically manipulated syllabic stress, rather than letter voicing. The subjects made more errors on targets occurring in unstressed than in stressed syllables. We interpret these results as indicating that the phonetic representation of text may be scanned at the level of the syllable, rather than at the level of the letter. The observation that the effects of syllable stress and word frequency were greatly diminished in passages in which every other letter was typed in capitals supports the view that both these effects operate at levels above the level of the letter. In addition, the observation that the effect of stress is most evident for the more frequent words supports our hypothesis that such words tend to be processed in syllable-size units.

We also found in Experiment 3 that the effects of word frequency and syllabic stress were most marked for targets in the second and third syllables of test 
multisyllabic words. These data suggest that the initial syllables of multisyllabic words are processed to the point of letter identification, regardless of the test word frequency or its syllabic stress pattern.

These results are consistent with the basic notion originally put forth by Corcoran (1966) that subjects looking for target letters scan a phonetically recoded version of text during silent reading. However, the phonetic units scanned do not appear to be at the letter level, but rather, at the level of the syllable. Our data suggest that these syllable units are formed only under certain conditions; their formation depends on word frequency, on the location of the syllable within the word, and on the visual features of printed text. The present study thus reconciles two distinct hypotheses regarding the reading process, phonetic recoding and unitization, and places these hypotheses within a single theoretical framework.

\section{REFERENCES}

Chen, K. Acoustic image in visual detection for deaf and hearing college students. Journal of General Psychology, 1976, 94, 243-246.

Coltheart, M., Hull, E., \& Slater, D. Sex differences in imagery and reading. Nature, 1975, 253, 438-440.

Corcoran, D. W. J. An acoustic factor in letter cancellation. Nature, 1966, $210,658$.

Drewnowski, A. Detection errors on the word the: Evidence for the acquisition of reading levels. Memory \& Cognition, $1978,6,403-409$.

Drewnowsk1, A. Missing -ing in reading: Developmental changes in reading units. Journal of Experimental Child Psychology, 1981, 31, 154-168.

Drewnowski, A., \& Healy, A. F. Detection errors on the and and: Evidence for reading units larger than the word. Memory \& Cognition, 1977, 5, 636-647.

Drewnowski, A., \& Healy, A. F. Missing -ing in reading: Letter detection errors on word endings. Journal of Verbal Learning and Verbal Behavior, 1980, 19, 247-262.

Foss, D. J., \& Blank, M. A. Identifying the speech codes. Cognitive Psychology, 1980, 12, 1-31.

Healy, A. F. Detection errors on the word the: Evidence for reading units larger than letters. Journal of Experimental
Psychology: Human Perception and Performance, 1976, 2, 235-242.

Healy, A. F. Proofreading errors on the word the: New evidence on reading units. Journal of Experimental Psychology: Human Perception and Performance, 1980, 6, 45-57.

Kučera, H., \& Francis, W. N. Computational analysis of present-day American English. Providence, R.I: Brown University Press, 1967.

LaBerae, D., \& Samuels, S. J. Toward a theory of automatic information processing in reading. Cognitive Psychology, 1974, 6, 293-323.

Locke, J. L. Phonemic effects in the silent reading of hearing and deaf children. Cognition, 1978, 6, 175-187.

McCusker, L. X., Hillinaer, M. L., \& Bias, R. G. Phonological recoding and reading. Psychological Bulletin, 1981, 89, 217-245.

Mohan, P. J. Acoustic factors in letter cancellation:Developmental considerations. Developmental Psychology, 1978, 14, 117-118.

Schindlen, R. M. The effect of prose context on visual search for letters. Memory \& Cognition, 1978, 6, 124-130.

Smith, P. T., \& Groat, A. Spelling patterns, letter cancellation and the precessing of text. In P. A. Kolers, M. E. Wrolstad, \& H. Bouma (Eds.), Processing of visible language 1. New York: Plenum, 1979.

\section{NOTES}

1. With the exception of a few short function words (e.g., he), words ending in a single terminal pronounced $e$ are few and have a low frequency in the language (e.g., adobe, apostrophe). For that reason, we did not use an orthogonal manipulation of voicing and location. Similarly, there are no content words in English that are comparable in frequency to the common function words, and we did not attempt an orthogonal manipulation of word frequency and word function.

2. As far as we can tell, our division of words into those with pronounced or silent es corresponds to the syllabic/nonsyllabic classification of Smith and Groat (1979). The one exception is the word "values," which would have been classified by them as a syllabic e but was classified by us as a silent $e$.

(Received for publication March 19, 1981; revision accepted January 8,1982 .) 